\title{
Infrequent K-ras codon 12 mutation in serrated adenomas of human colorectum
}

\author{
Y Ajioka, H Watanabe, J R Jass, Y Yokota, M Kobayashi, K Nishikura
}

\begin{abstract}
Background-Serrated adenoma is a new morphological subtype of colorectal adenoma. The lesion provides a distinct morphological route to carcinoma, but the underlying genetic changes have not yet been investigated.
\end{abstract}

Aims-To determine the frequency of $\mathrm{K}$-ras mutation in serrated adenoma.

Methods-The frequency of K-ras codon 12 point mutation in 20 serrated adenomas, five atypical hyperplastic polyps, and 58 sporadic polypoid adenomas was investigated by nested polymerase chain reaction-restriction fragment length polymorphism (PCR-RFLP) methods.

Results-Although most of the serrated adenomas were large (average size 11.4 $\mathrm{mm}$ ) and polypoid, $\mathrm{K}-\mathrm{ras}$ codon 12 point mutation was detected in only one of the $20(5 \%)$, which is a significantly lower frequency than that in sporadic polypoid adenomas $(18 / 60 ; 30 \%)(p=0.017)$. No mutation was detected in the atypical hyperplastic polyps. Three of $20(15 \%)$ serrated adenomas contained a focus of carcinoma in situ, indicating their malignant potential and the existence of a serrated adenoma-carcinoma sequence, but no mutation was detected in the foci of carcinoma in situ.

Conclusions-K-ras mutation is uncommon in serrated adenomas, indicating a different spectrum of genetic alterations in these lesions from those in typical polypoid sporadic adenomas. This subtype of colorectal adenoma represents a new genetic pathway in the histogenesis of colorectal carcinoma.

(Gut 1998;42:680-684)

Keywords: serrated adenoma; colorectal adenoma; $\mathrm{K}$-ras mutation; PCR-RFLP

Pathology, Medical

School, University of

Queensland,

Queensland, Australia

J R Jass

Third Department of Internal Medicine, School of Medicine, Niigata University M Kobayashi

Correspondence to: Dr Y Ajioka, First Department of Pathology, School of Medicine, Niigata University,

1-Asahimachi-dori, Niigata, Japan.

Accepted for publication 31 October 1997

Serrated adenoma is a new morphological subtype of colorectal adenoma, as proposed by Longacre and Fenoglio-Preiser in 1990. ${ }^{1}$ The polyp combines the morphological features of hyperplastic and adenomatous epithelium. It shows a serrated glandular architecture reminiscent of hyperplastic polyps, but the cytological features (incomplete mucinous differentiation, pseudostratified and enlarged spindle shaped nuclei) and lack of surface maturation indicate its neoplastic nature. It has been separated from mixed polyps comprising a mixture or "collision" of readily identified hyperplastic and adenomatous components. ${ }^{1}$ Although the incidence of serrated adenomas has been estimated as less than $1 \%$ of all colorectal polyps, malignant potential is thought to exceed that of typical adenomas. ${ }^{1}$ Attention has also been focused on the relation between giant hyperplastic polyps and hyperplastic polyposis. ${ }^{23}$ Genetic changes in these lesions have not been investigated previously.

APC and K-ras mutations are important alterations in the morphogenesis of colorectal adenomas, ${ }^{45}$ the APC mutation initiating microadenoma $^{5}$ and K-ras mutations, predominantly in codon $12,{ }^{467}$ being associated with progression. ${ }^{4}$ In this study, we focused on analysis of $\mathrm{K}$-ras codon 12 point mutations in serrated adenomas of the colon and rectum and compared them with sporadic polypoid tubular adenomas. K-ras codon 12 mutation was found to be infrequent in serrated adenomas, indicating a different genetic pathway of change in this new subtype of colorectal adenomas.

\section{Methods}

SPECIMEN

Formalin fixed, paraffin embedded blocks were obtained from endoscopically resected serrated adenomas (20), atypical hyperplastic polyps (five), and sporadic polypoid tubular adenomas (60, including ones in our previous study ${ }^{8}$ ). Serrated adenomas were defined as polyps composed of serrated glands reminiscent of hyperplastic polyps on low power magnification, but the serrated epithelium showed neoplastic cytological atypia: pseudostratification of enlarged and/or elongated spindle

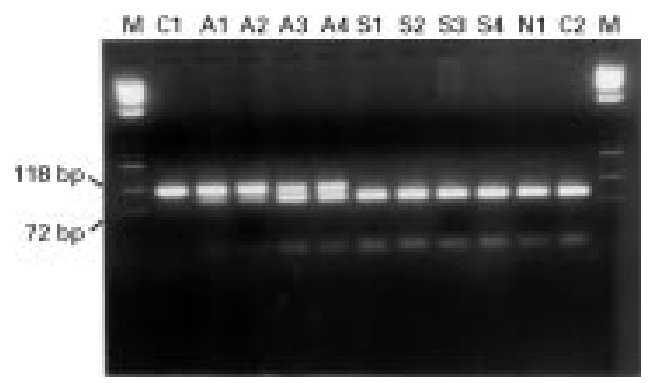

Figure 1 Nested polymerase chain reaction-restriction fragment length polymorphism (PCR-RFLP) analysis of $K$-ras codon 12 mutations in serrated adenomas and sporadic traditional polypoid adenomas. The wild type and mutant fragments were detected at 86 and $106 \mathrm{bp}$ respectively. $M, \Phi X 174 /$ HaeIII DNA size marker; lane $C 1$, positive mutant control (AsPcl1) homozygous for mutant K-ras at codon 12 showing uncleaved mutant band (106 bp) only; lane C2, normal control (normal human placental DNA) showing cleaved wild type band ( $86 \mathrm{bp}$ ) only; lanes $A 1$ to $A 4, D N A$ samples from polypoid adenomas showing both mutant and wild type bands (heterozygous); lanes $S 1$ to S4, DNA samples from serrated from normal colorectal tissue with wild type band only. No negative control is shown. adenoma with wild type band only; lane N1, DNA sample 
A
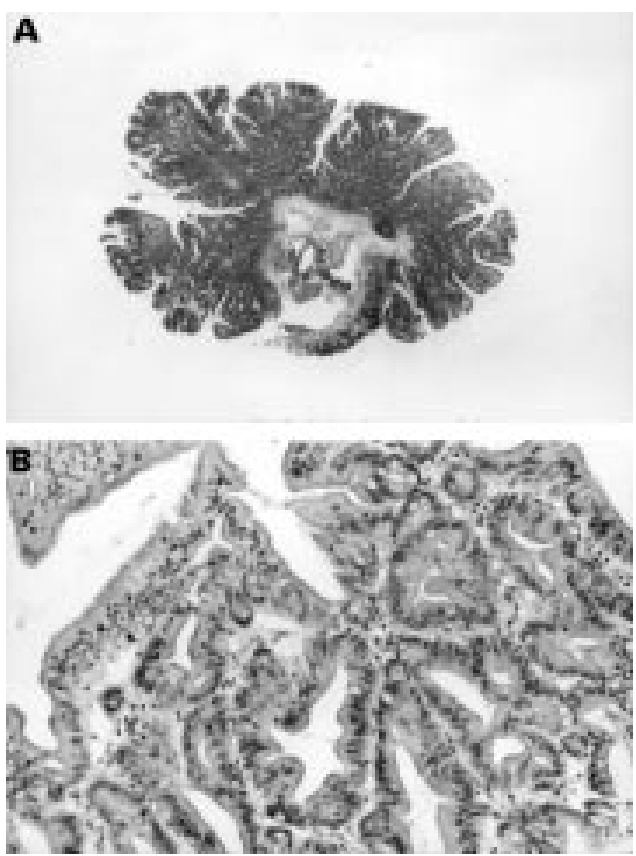

Figure 2 (A) Whole mount view of serrated adenoma that was almost pure histologically, measuring $9 \mathrm{~mm}$ in size with subpedunculated configuration (original magnification $\times 2.5$ ). (B) The serrated glandular architecture is reminiscent of a hyperplastic polyp but its cytology (pseudostratified enlarged and/or spindle shaped nuclei with loss of goblet cells) and lack of surface maturation indicate its neoplastic nature (original magnification $\times 50$ ).

shaped nuclei, loss of mature goblet cells, a dark eosinophilic cytoplasm and lack of surface maturation, and lack of the thickened collagen table at the free surface. ${ }^{1}$ The distinction between serrated adenoma and hyperplastic polyps was not always straightforward. All uncertain cases were grouped separately as "atypical hyperplastic polyps" (AHP). Serrated adenomas were either pure (SA) or accompanied by AHP (SA+AHP) or typical hyperplastic polyps $(\mathrm{SA}+\mathrm{HP})$. Lesions that appeared as a "collision" or intermingling of typical hyper- plastic and adenomatous epithelium ${ }^{1}$ were carefully excluded from the study. Serial sections 3 and $10 \mu \mathrm{m}$ thick were prepared for each specimen. The $3 \mu \mathrm{m}$ thick section was used for haematoxylin and eosin staining and the $10 \mu \mathrm{m}$ thick section for DNA extraction.

DNA EXTRACTION AND ANALYSIS OF K-RAS CODON 12 MUTATION

DNA was extracted as described previously. ${ }^{8}$ When a lesion was histologically heterogeneous (composed of serrated adenoma and/or hyperplastic polyps, atypical hyperplastic polyps, carcinoma in situ), DNA was extracted separately from each individual area by microdissection. DNA samples from normal colorectal tissue were also extracted if present in the specimen. The K-ras codon 12 point mutation was analysed by the nested polymerase chain reaction-restriction fragment length polymorphism (PCR-RFLP) method. PCR amplification was performed using the primers and conditions described by Ooshima et al, ${ }^{10}$ except that annealing was carried out for 1.5 minutes. In each PCR run, three control reactions were included: (a) negative control (containing no template DNA); (b) normal control (normal human placental DNA); (c) positive control (AsPcl pancreas cancer cell line DNA which contains a homozygously mutant K-ras codon 12: GTT to GAT $^{11}$ ). RFLP was carried out by established methods $^{8-10}:$ PCR products $(10 \mu \mathrm{l})$ were incubated with $1 \mu \mathrm{l}$ Mval (Takara, Kyoto, Japan) at $37^{\circ} \mathrm{C}$ for six hours, electrophoresed in $3.5 \%$ NuSieve agarose gel (FMC Bioproducts, Rockland, ME, USA), and stained with ethidium bromide. The wild type PCR products were cleaved, resulting in a band of $86 \mathrm{bp}$ fragments (fig 1). In each electrophoretic run, a normal control (normal human placental DNA) always showed a single band of $86 \mathrm{bp}$ fragments, ruling out the possibility of partial digestion with the restriction enzyme. Any PCR products containing $106 \mathrm{bp}$ fragments

Table 1 Number, size and macroscopic type of lesion

\begin{tabular}{|c|c|c|c|c|c|}
\hline & \multirow[b]{2}{*}{ No } & \multicolumn{2}{|c|}{ Average size ( $m m$ (range)) } & \multicolumn{2}{|c|}{ Macroscopic type } \\
\hline & & Whole lesion & Area of $S A$ & Sessile & Protuberant \\
\hline AHP & 5 & $5.2(3-7)$ & - & 3 & 2 \\
\hline $\mathrm{SA}$ & 11 & $11.8(7-24)$ & $11.8(7-24)$ & 0 & 11 \\
\hline $\mathrm{SA}+\mathrm{HP}$ & 3 & $8.7(8-10)$ & $6.0(5-7)$ & 2 & 1 \\
\hline $\mathrm{SA}+\mathrm{AHP}$ & 6 & $12.0(6-18)$ & $8.0(3-17)$ & 2 & 4 \\
\hline
\end{tabular}

AHP, atypical hyperplastic polyp; SA, lesion composed purely of serrated adenoma; SA+HP, serrated adenoma accompanied by a hyperplastic polyp; SA+AHP, serrated adenoma accompanied by an atypical hyperplastic polyp.

Table 2 Frequency of K-ras codon 12 mutations in serrated adenomas, atypical hyperplastic polyps and sporadic polypoid adenomas

\begin{tabular}{|c|c|c|c|c|c|c|}
\hline & \multicolumn{6}{|c|}{ K-ras (codon 12) mutation by size ( $\mathrm{mm}$ ) and total } \\
\hline & $X \leqslant 5$ & $5<X<10$ & $X \geqslant 10$ & Total & & \\
\hline AHP & $0 / 1(0)$ & $0 / 4(0)$ & - & $0 / 5(0)$ & & \\
\hline SA & - & $0 / 5(0)$ & $0 / 6(0)$ & $0 / 11(0)$ & & \\
\hline $\mathrm{SA}+\mathrm{HP} / \mathrm{AHP}$ & - & $1 / 3^{\star}(33.3)$ & $0 / 6(0)$ & $1 / 9(11.1)$ & & $\ddagger$ \\
\hline All SA foci & $1 / 4(25.0)$ & $0 / 8(0)$ & $0 / 8(0)$ & $1 / 20(5.0)$ & $t$ & \\
\hline $\mathrm{AD}$ (polypoid) & $0 / 10(0)$ & $6 / 25(24.0)$ & $12 / 25(48.0)$ & $18 / 60(30.0)$ & & \\
\hline
\end{tabular}

Values in parentheses are percentages.

AHP, atypical hyperplastic polyp; SA, lesion composed purely of serrated adenoma; SA+HP/AHP, serrated adenoma accompanied by hyperplastic polyp or atypical hyperplastic polyp; all SA foci, data confined to area of serrated adenoma; AD, sporadic tubular adenoma.

${ }^{\star} \mathrm{K}$-ras point mutation was detected only in the area of serrated adenoma.

$\mathrm{tp}=0.017(1 / 20 v 18 / 60) ; \ddagger \mathrm{p}=0.18(0 / 5 \vee 18 / 60)$. 
(not cleaved by Mval) were considered to contain a mutation at codon 12 .

\section{STATISTICAL ANALYSIS}

Statistical analysis was by Fisher's exact test. A $\mathrm{p}$ value of less than 0.05 was regarded as significant.

\section{Results}

MORPHOLOGICAL FINDINGS

Of the 20 serrated adenomas, 11 (55\%) were almost histologically pure (SA) (fig 2), six $(30 \%)$ were accompanied by atypical hyperplastic polyps (SA+AHP), and three (15\%) were accompanied by traditional hyperplastic polyps (SA+HP) (figs 3 and 4, table 1). The mean (SD) size of the serrated adenomas including accompanying atypical hyperplastic polyps or hyperplastic polyps was 11.4 (3.9) $\mathrm{mm}$ and that of the serrated adenomatous component alone was $9.6(5.0) \mathrm{mm}$. Sixteen of $20(80 \%)$ were protuberant macroscopically. In protuberant polyps, serration was prominent
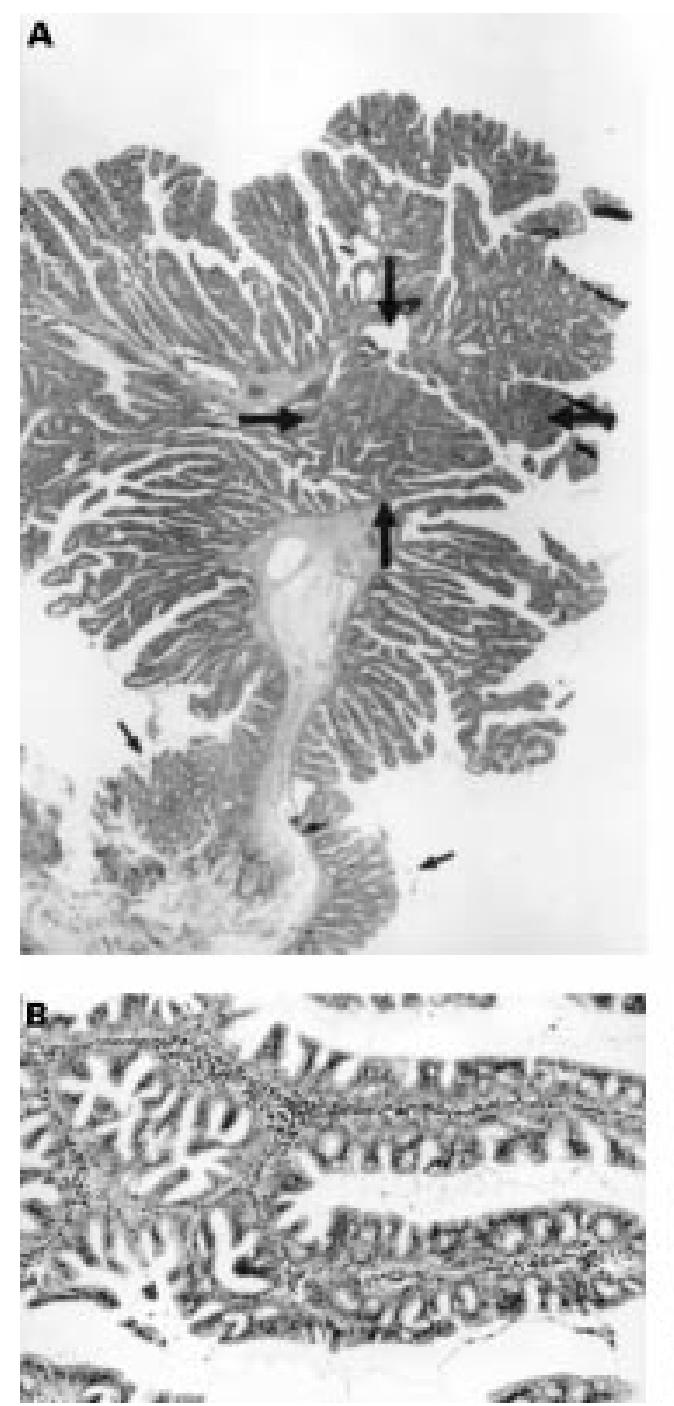

and seen throughout most if not all the lesion (figs 2 and 3), but it tended to be slight in sessile lesions (fig 4). Two lesions in SA+AHP and one in SA+HP contained a focus of severe atypia equivalent to carcinoma in situ (fig 3 ). This comprised closely spaced serrated glands with focal back to back or pseudocribriform appearance and round to ovoid vesicular nuclei with prominent nucleoli. Atypical hyperplastic polyps (including AHP in SA+AHP) were histologically characterised by irregularly branched serrated glands with loss of goblet cells and the presence of numerous dystrophic goblet cells, oval to spindle shaped nuclei with slight pseudostratification, and a small degree of surface maturation (fig 5). The average size of atypical hyperplastic polyps was $5.2 \mathrm{~mm}$ (all of them were less than $10 \mathrm{~mm}$ ), but two of the five $(40 \%)$ were protuberant.

K-RAS CODON 12 POINT MUTATION

The K-ras mutation in serrated adenomas was detected in one of $20(5 \%)$ (table 2 ). The ser-
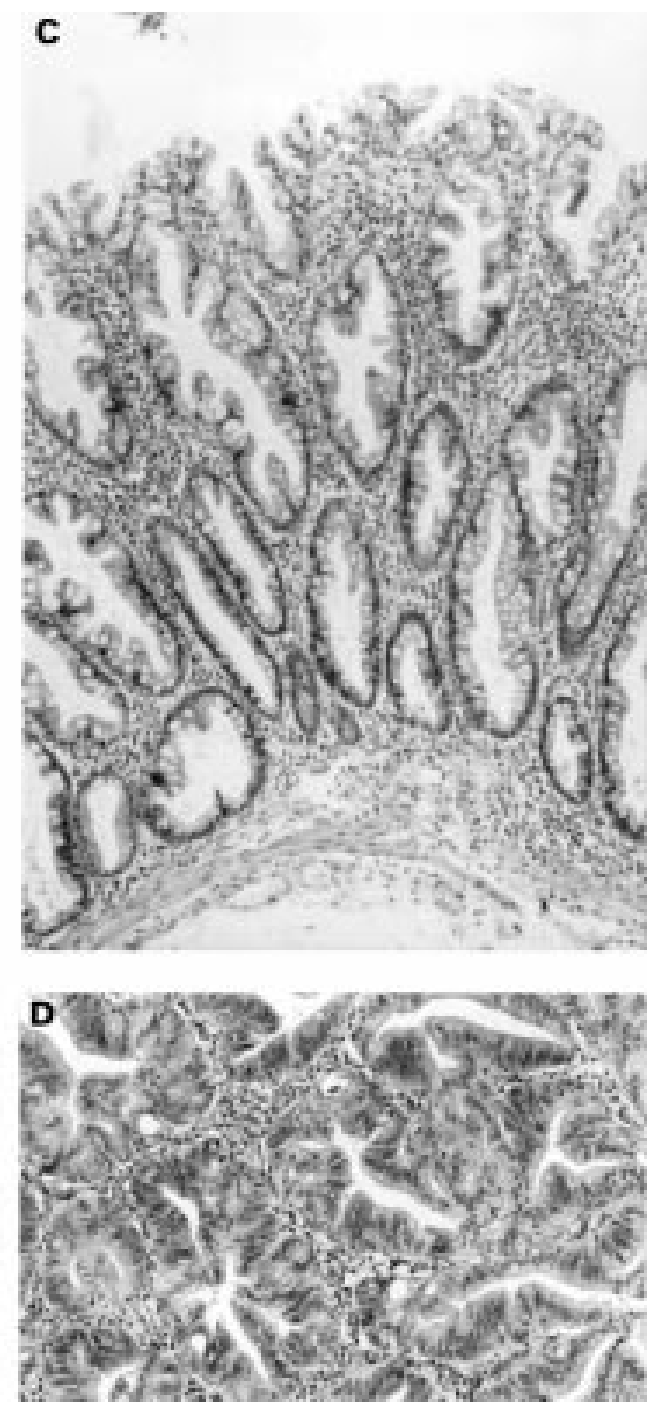

Figure 3 (A) Whole mount view of serrated adenoma accompanied by hyperplastic polyps and focus of severe atypia, equivalent to carcinoma in situ, measuring $12 \mathrm{~mm}$ in size with pedunculated configuration (original magnification $\times 2.5$ ). (B) Serrated adenoma with enlarged nuclei with prominent nucleoli (original magnification $\times 40$ ). (C) Hyperplastic polyp accompanied by serrated adenoma located at the periphery of the lesion (indicated by the small arrows in $(A)$ ) (original magnification $\times 25$ ). (D) Focus of carcinoma in situ located at the centre of the lesion (indicated by the large arrows in (A)) (original magnification $\times 50$ ). 


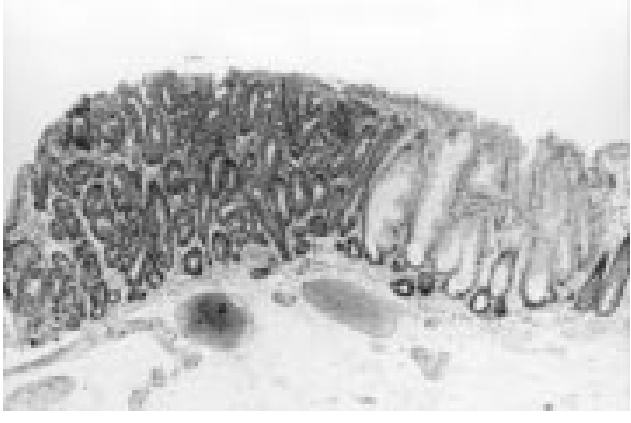

Figure 4 Serrated adenoma adjoining hyperplastic polyp, measuring $8 \mathrm{~mm}$ with sessile configuration (original magnification $\times 13.2$ ). Area of serrated adenoma (left half of the lesion) measuring $5 \mathrm{~mm}$, showing slight but definite luminal serration. K-ras mutation was detected only in the area of serrated adenoma.

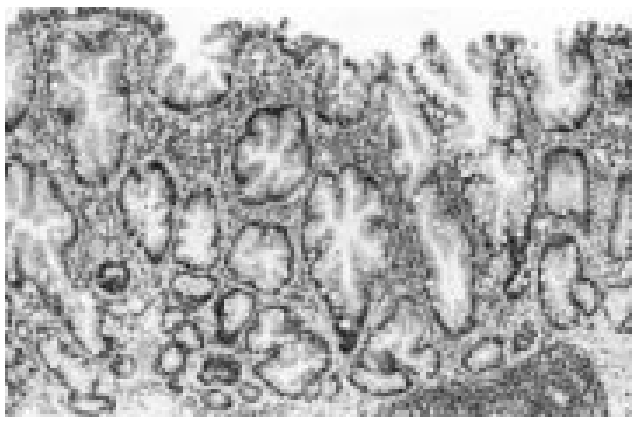

Figure 5 Atypical hyperplastic polyp showing irregular glandular structure, numerous dystrophic goblet cells, and a slight degree of surface maturation (original magnification $\times 25$ ).

rated adenoma with a $\mathrm{K}$-ras mutation was a sessile $8 \mathrm{~mm}$ size lesion accompanied by hyperplastic polyps (SA+HP) (fig 4 ). The serrated adenoma component measured $5 \mathrm{~mm}$. DNA was extracted separately from the areas of serrated adenoma and hyperplastic polyp, and the mutation was detected only in the serrated adenoma. No mutation was detected in atypical hyperplastic polyps, foci of carcinoma in situ, or normal colorectal tissue. The frequency of K-ras mutation in traditional polypoid tubular adenomas was 30\% (18/60). Mutation rate increased with size; $48 \%(12 / 25)$ of adenomas larger than $10 \mathrm{~mm}$ had a mutation. Statistical significance was observed between polypoid adenomas (30\%) and serrated adenomas (all SA foci) $(5 \%)(p=0.017)$, and trend between polypoid adenomas and atypical hyperplastic polyp $(0 \%)(\mathrm{p}=0.18)$.

\section{Discussion}

The frequency of $\mathrm{K}$-ras codon 12 mutation in serrated adenomas was $5 \%$, which is significantly lower than that of control sporadic polypoid adenomas $(30 \%)$. K-ras mutation, predominantly in codon 12, may result in subclonal evolution of colorectal adenomas, represented morphologically as an increase in size and grade of atypia. ${ }^{12}$ About $60-70 \%$ of adenomas larger than $10 \mathrm{~mm}$ have been shown to have a K-ras mutation. ${ }^{413}$ However, this observation is based on sporadic polypoid colorectal adenomas, ${ }^{14}$ whereas K-ras mutation is infrequent in flat type adenomas. ${ }^{15}{ }^{16}$ The role of K-ras point mutation in morphogenesis of colorectal adenomas has not been elucidated in detail, although it is known to up regulate mitogenic signal transduction pathways. ${ }^{17}$ The high mutation frequency in polypoid adenomas as opposed to flat adenomas suggests that K-ras mutation may be related not only to increase in size but more specifically to polypoid adenoma growth. ${ }^{816}$ The single serrated adenoma found to be positive for K-ras mutation in our study was a small and sessile lesion (the whole lesion measured $8 \mathrm{~mm}$, but the area of serrated adenoma was confined to $5 \mathrm{~mm}$ ), and no mutation was found in other larger protuberant polyps. Our data indicate that K-ras mutation is not related to morphogenesis of serrated adenomas and indicate a different spectrum of genetic alterations in these lesions.

Although the concept of serrated adenoma has been generally accepted, their diagnosis may not be straightforward. ${ }^{2}$ A histological spectrum exists within serrated adenomatous epithelial proliferations, ranging from those that are more like traditional adenoma to those that are more like hyperplastic polyp. ${ }^{2}$ Further histological subclassification of serrated adenoma may be needed. All serrated adenomas in this study fulfilled the histological criteria of the original report. ${ }^{1}$ Some traditional adenomas produce a pattern superficially reminiscent of luminal serration by virtue of multiglandular budding and branching, and they were excluded from the study. Serrated adenomas with an adenoma-like appearance by virtue of definite but slight serration (fig 4) were included, and accounted for the single instance of a serrated adenoma with K-ras mutation. At the other end of the spectrum, serrated polyps with indefinite adenomatous features were grouped as atypical hyperplastic polyps. They could not be judged as serrated adenoma because of incomplete but definite surface maturation. Like typical hyperplastic polyps, they were small, but two of the five were protuberant. Atypical hyperplastic polyps showed glandular irregularities and dystrophic goblet cells as described in dysplasia in ulcerative colitis. ${ }^{18}$ The presence of such foci in $30 \%$ of the serrated adenomas suggests that the atypical hyperplastic polyp may belong within the spectrum of serrated adenoma or its precursor lesion.

Intramucosal carcinoma has been reported to occur in $10 \%$ of serrated adenomas, indicating that serrated adenomas have significant malignant potential. ${ }^{1}$ In our material, $15 \%$ of the serrated adenomas included a focus of severe atypia, equivalent to carcinoma in situ. Cases of invasive carcinoma with distinct serrated configuration have been reported. ${ }^{2}{ }^{19}$ Colorectal carcinomas are thought to arise through three main histogenic pathways: (1) classical of polypoid adenoma-carcinoma sequence ${ }^{2021}$; (2) flat adenoma-carcinoma sequence $^{22} 23$; (3) de novo cancerisation. ${ }^{24} 25$ Serrated adenoma-carcinoma sequence would represent a fourth pathway. With regard to the associated genetic alterations, K-ras mutation is involved in polypoid adenoma-carcinoma sequence, but not in the flat adenomacarcinoma sequence (as above) or in intramu- 
cosal carcinomas thought to arise de novo. ${ }^{26}$ These differences allow the K-ras mutation to serve as genetic marker of histogenesis. ${ }^{27}$ Since the frequency of K-ras mutation in colorectal cancers is about $50 \%{ }^{28}(30-40 \%$ with a mutation at codon $12^{467}$ ), at least this proportion would have originated from polypoid adenomas. The serrated adenoma-carcinoma sequence will apply to a subset of these cancers lacking a K-ras mutation.

We thank our laboratory staff for their excellent technical support. The AsPcl cell line was provided by Dr Ken Yamaguch (National Cancer Center Research Institute, Tokyo, Japan).

1 Longacre TA, Fenoglio-Preiser CM. Mixed hyperplastic adenomatous polyps/serrated adenomas. A distinct form of colorectal neoplasia. Am f Surg Pathol 1990;14:524-37.

2 Jeevaratnam P, Cottier DS, Browett PJ, et al. Familial giant hyperplastic polyposis predisposing to colorectal cancer: a new hereditary bowel cancer syndrome. F Pathol 1996;179: new.

3 Torlakovic E, Snover DC. Serrated adenomatous polyposis in humans. Gastroenterology 1996;110:748-55.

4 Vogelstein B, Fearon ER, Hamilton SR, et al. Genetic alteraVogelstein B, Fearon ER, Hamilton SR, et al. Genetic alterations during colo

5 Powell SM, Zilz N, Beazer-Barclay Y, et al. APC mutations occur early during colorectal tumorigenesis. Nature 1992; 359:235-7.

6 Forrester K, Almoguera C, Hank K, et al. Detection of high incidence of K-ras oncogenes during human colon tumorigenesis. Nature 1987;327:298-303.

7 Bos JL, Fearon ER, Hamilton SR, et al. Prevalence of ras gene mutations in human colorectal cancers. Nature 1987; 327:293-7.

8 Kobayashi M, Watanabe H, Ajioka Y, et al. Effect of K-ras mutation on morphogenesis of colorectal adenomas and early cancers; relationship to distribution of proliferating cells. Hum Pathol 1996;27:1042-9.

9 Itoi T, Watanabe H, Ajioka Y, et al. APC, K-ras codon mutations and p53 gene expression in carcinoma and mutations and p53 gene expression in carcinoma and in gall-bladder carcinogenesis. Pathol Int 1996;46:333-40.

10 oshima S, Shimizu Y, Takahama M. Detection of c-Ki-ras gene mutation in paraffin sections of adenocarcinoma and atypical bronchioloalveolar cell hyperplasia of human lung. Virchows Arch 1994;424:129-34.
11 Berrozpe G, Schaeffer J, Peinado MA, et al. Comparative analysis of mutations in the p53 and K-ras genes in pancreatic cancer. Int $\mathcal{F}$ Cancer 1994;58:185-91.

12 Ilyas $M$, Tomlinson IPM. Genetic pathways in colorectal cancer. Histopathology 1996;28:389-99.

13 Boughdady I, Kinsella AR, Haboubi NY, et al. K-ras gene mutations in adenomas and carcinomas of the colon. Surg Oncol 1992;1:275-82.

14 McLellan EA, Owen RA, Stepniewska KA, et al. High frequency of K-ras mutations in sporadic colorectal adenomas. Gut 1993;34:392-6.

15 Fujimori T, Satonaka K, Yamamura-ldei Y, et al. Noninvolvement of ras mutation in flat colorectal adenomas and carcinomas. Int f Cancer 1994;57:51-5.

16 Yamagata S, Muto T, Uchida Y, et al. Lower incidence of K-ras codon- 12 mutation in flat colorectal adenomas than in polypoid adenomas. Fpn F Cancer Res 1994;85:147-51.

17 Bos JL. The ras gene family and human carcinogenesis. Mutat Res 1988;195:255-71.

18 Riddell RH, Goldman H, Ransohoff DF, et al. Dysplasia in inflammatory bowel disease: standardized classification with provisional clinical applications. Hum Pathol 1983;14: 931-68.

19 Jass JR, Smith M. Sialic acid and epithelial differentiation in colorectal polyps and cancer: a morphological, mucin and lectin histochemical study. Pathology 1992;24:233-42.

20 Muto T, Bussey HJ, Morson BC. The evolution of cancer of the colon and rectum. Cancer 1975;36:2251-70.

21 Morson BC, Dawson IMP. Adenomas and the adenomacarcinoma sequence. In: Morson BC, Dawson IMP, eds. Gastrointestinal pathology, 2nd ed. Oxford: Blackwell, 1979: 615-47.

22 Muto T, Kamiyama J, Sawada T, et al. Small "flat adenoma" of the large bowel with special reference to its clinicopathological features. Dis Colon Rectum 1985;28:847-51.

23 Adachi M, Muto T, Morioka Y, et al. Flat adenoma and flat mucosal carcinoma (Ilb Type): a new precursor of colorectal carcinoma? Dis Colon Rectum 1988;31:236-43.

24 Kuramoto S, Oohara T. Minute cancers arising de novo in the human large intestine. Cancer 1988;61:829-34.

25 Shimoda T, Ikegami M, Fujisaki J, et al. Early colorectal carcinoma with special reference to its development de novo. Cancer 1989;64:1138-46.

26 Aoki T, Takeda S, Yanagisawa A, et al. APC and pS3 mutations in de novo colorectal adenocarcinomas. Hum Mutat 1994;3:342-6.

27 Hasegawa $\mathrm{H}$, Ueda $\mathrm{M}$, Watanabe $\mathrm{M}$, et al. K-ras gene mutations in early colorectal cancer: flat elevated vs polypforming cancer. Oncogene 1995;10:1413-16.

28 Fearon ER, Vogelstein B. A genetic model for colorectal tumorigenesis. Cell 1990;61:759-67. 